\title{
Influência do uso do rbST sobre a saúde de vacas Holandesas no período de transição
}

Raquel Grden Szinvelski[ ${ }^{[]^{*}}$, Tiago de Oliveira Carneiro ${ }^{[b]}$, Jean Silva Ramos ${ }^{[a]}$, Ana Elisa Negrão Pereira Barreto ${ }^{[b]}$, Jessica Cristina Bertoni $^{\left[{ }^{[b]},\right.}$, Juliana França dos Reis Costa ${ }^{[b]}$, Viviani Gomes ${ }^{[a]}$

\footnotetext{
[a] Faculdade de Medicina Veterinária e Zootecnia, Universidade de São Paulo (USP), São Paulo, SP, Brasil

[b] J. Ida Agropecuária Ltda., São João da Boa Vista, SP, Brasil
}

*Autor correspondente

e-mail: raquelgs.mv@gmail.com

\section{Resumo}

O elevado escore de condição corporal (ECC) na secagem está associado à redução na ingestão de matéria seca, que resulta em estresse metabólico e imunossupressão, associada à maior ocorrência de doenças no período pós-parto. 0 uso do rbST, sigla proveniente do inglês recombinant bovine somatotropin, representa uma estratégia para aumentar a concentração do IGF-I (Insulin like growth factor), que atua no crescimento e diferenciação celular. Este fator está associado com a regulação da resposta imune inata e específica que, consequentemente, refletirá em menores índices de doenças. 0 presente trabalho relata um estudo retrospectivo a partir da análise de dados obtidos entre julho e agosto de 2016 em uma fazenda leiteira com produção média equivalente a 13.000 litros/dia (26 litros/vaca), localizada em São João da Boa Vista/ SP. Foram analisados os registros de 63 vacas Holandesas multíparas com o escore de condição corporal (ECC) igual ou superior a 3,75. Estes animais receberam de 1 a 3 aplicações (166 mg, dose 0,46 mL) de bST (Lactotropin ${ }^{\circledR}$, Elanco) em diferentes momentos pré-parto: o grupo 1 (G1, $n=21$ ) recebeu somente uma dose de bST no dia -21; o grupo 2 (G2, n = 25) recebeu bST nos dias -21 e -14; e o grupo 3 (G3, n=17) recebeu bST nos dias -21, -14 e -7. 0 escore na parição e ocorrência de doenças foi analisado pelo teste do qui-quadrado. Das 63 vacas selecionadas para o estudo, somente 37 foram submetidas à avaliação de ECC ao parto. A frequência de vacas com ECC $\geq 3,75$ no parto foi de 46,2\% (6/13) no G1, 37,5\% (3/8) no G2 e 18,8\% (3/16) no G3. Não houve associação entre o ECC e os diferentes tratamentos (P $\geq 0,05$ ), porém, as vacas do G3 apresentaram menor frequência de animais com ECC $\geq 3,75$ na parição. Em relação à saúde, as vacas foram categorizadas de acordo com a ausência (saudáveis) ou presença (doentes) de ao menos uma enfermidade no período pósparto. A frequência de vacas doentes no pós-parto foi de 33,3\% (7/21) no G1, 28\% (7/25) no G2 e 29,4\% 
(5/17) no G3. Através da análise do teste estatístico qui-quadrado foi possível observar que a ocorrência de doenças no pós-parto não teve associação com os grupos experimentais $(P=0,05)$. 0 tratamento dos animais com 3 doses de bST no pré-parto diminuiu a frequência de vacas obesas ao parto, porém, o baixo $n$ amostral pode ter influenciado a não obtenção dos resultados significativos, tanto para o ECC quanto para a ocorrência de doenças. Além disso, existe a necessidade de estudos futuros para a padronização da dose de bST estimuladora do sistema imune. 